\title{
Water Storage Changes over the Tibetan Plateau Revealed by GRACE Mission
}

\author{
Jinyun GUO ${ }^{1,2}$, Dapeng $\mathrm{MU}^{1,3}$, Xin $\mathrm{LIU}^{1}$, Haoming $\mathrm{YAN}^{3}$, \\ Zhongchang $\mathrm{SUN}^{4}$, and Bin $\mathrm{GUO}^{1,2}$
}

${ }^{1}$ College of Geodesy and Geomatics, Shandong University of Science and Technology, Qingdao, China; e-mail: jinyunguo1@126.com

${ }^{2}$ State Key Laboratory of Mining Disaster Prevention and Control Co-founded by Shandong Province and Ministry of Science and Technology,

Shandong University of Science and Technology, Qingdao, China

${ }^{3}$ State Key Laboratory of Geodesy and Earth's Dynamics, Institute of Geodesy and Geophysics, Chinese Academy of Science, Wuhan, China

${ }^{4}$ Institute of Remote Sensing and Digital Earth, Chinese Academy of Science, Beijing, China

\begin{abstract}
We use GRACE gravity data released by the Center for Space Research (CSR) and the Groupe de Recherches en Geodesie Spatiale (GRGS) to detect the water storage changes over the Tibetan Plateau (TP). A combined filter strategy is put forward to process CSR RL05 data to remove the effect of striping errors. After the correction for GRACE by GLDAS and ICE-5G, we find that TP has been overall experiencing the water storage increase during 2003-2012. During the same time, the glacier over the Himalayas was sharply retreating. Interms of linear trends, CSR's results derived by the combined filter are close to GRGS RL03 with the Gaussian filter of $300-\mathrm{km}$ window. The water storage increasing rates determined from CSR's RL05 products in the interior TP, Karakoram Mountain, Qaidam Basin, Hengduan Mountain, and middle Himalayas are 9.7, 6.2, 9.1, -18.6 , and $-20.2 \mathrm{~mm} / \mathrm{yr}$, respectively.
\end{abstract}

Ownership: Institute of Geophysics, Polish Academy of Sciences;

(C) 2016 Guo et al. This is an open access article distributed under the Creative Commons Attribution-NonCommercial-NoDerivs license,

http://creativecommons.org/licenses/by-nc-nd/3.0/. 
These rates from GRGS's RL03 products are 8.6, 5.8, 10.5, -19.3 and $-21.4 \mathrm{~mm} / \mathrm{yr}$, respectively.

Key words: GRACE, Tibetan Plateau, water storage, filter method, equivalent water height.

\section{INTRODUCTION}

The elevation of the Tibetan Plateau (TP) known as the third pole of the world is greater than $4000 \mathrm{~m}$. TP has been more and more important in the study of global change and geodynamics. Due to the high elevation, the glacial area of TP is about $160 \mathrm{~km}^{2}$ (see Fig. 1). On the background of global warming, the glaciers over TP have been sharply shrinking since the 1990s (Yao et al. 2013, Matsuo and Heki 2010).

Due to the limitation of data availability, it is very difficult to directly quantify the mass changes (e.g., glacier, groundwater, and surface water) over TP and the Himalayas (Kääb et al. 2012). The glacier area and mass variations detected by satellite imagery and satellite altimetry have great differences on TP. ICESat implied that the shrinkage of glacier in the Himalayas from 2003 to 2009 was $10-30 \mathrm{~mm} / \mathrm{yr}$ (Gardner et al. 2013). The digital elevation model showed the volume loss rate of 22 and $45 \mathrm{~cm} / \mathrm{yr}(1999$ 2008) in the east and west Himalayas, respectively (Gardelle et al. 2013). Gardelle et al. (2013) used earlier time series than the GRACE data used in our analysis. Comparing the mass loss in the Himalayas, GRACE mission indicated that the water mass over TP was increasing by $7 \mathrm{Gt} / \mathrm{yr}$ during

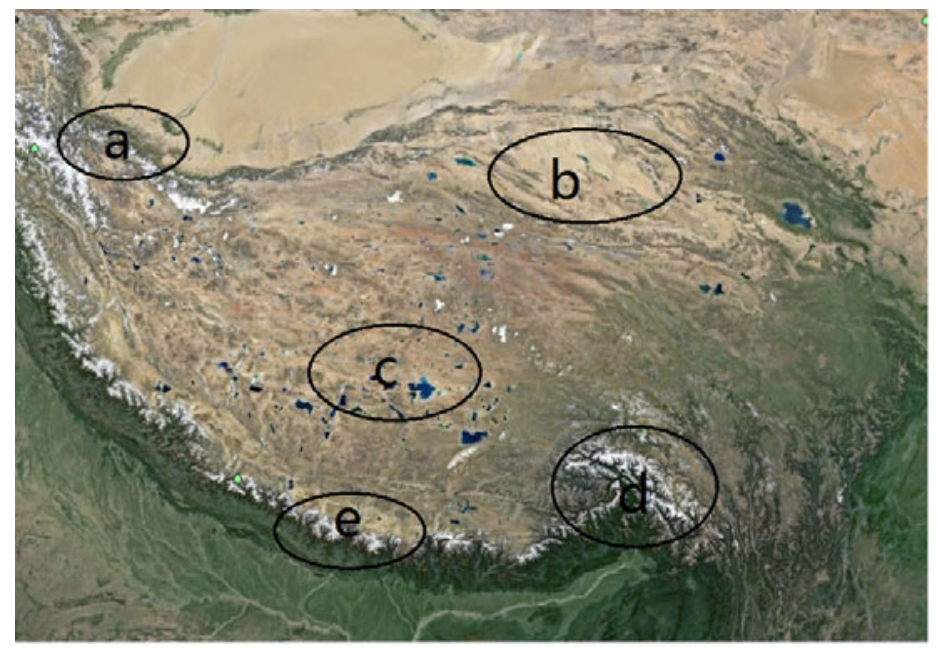

Fig. 1. Tibetan Plateau (from Google Earth): (a) Karakoram Mountain, (b) Qaidam Basin, (c) the middle TP, (d) Hengduan Mountain, and (e) the middle Himalayas are selected as black ellipsoids for further study. 
2003-2010 (Jacob et al. 2012). ICESat also demonstrated that water levels of most lakes in the interior TP were rising (Song et al. 2013, Zhang et al. 2013). All the investigations proved that the mass changes over TP and surrounding area (e.g., Himalayas) were spatially inhomogenous.

Since its successful launch, GRACE mission has been able to provide useful information of surface mass change in the large scale (Tapley et al. 2004). Because of different estimation methods and post-processing techniques, GRACE-derived mass changes varied (Guo et al. 2014, Ju et al. 2014, Mu et al. 2014), especially in regions with a weak geophysical signal. Taking the mascon approach, for example, a positive rate of $7 \mathrm{Gt} / \mathrm{yr}$ in TP was detected by the spectral domain inverse method from GRACE data (Jacob et al. 2012), while a positive rate of $30 \mathrm{Gt} / \mathrm{yr}$ was given by $\mathrm{Yi}$ and Sun (2014) with the space domain inverse method. This indicates that GRACE will deliver different estimates with different data processing strategies.

The main purpose of this paper is to investigate the water mass changes over TP by evaluating different GRACE solutions with different filter methods. Based on the time series of GRACE products (i.e., we assumed that GRACE-derived signals were dominated by the linear and periodic components), a combined filter which integrates the statistical filter approach (Davis et al. 2008), the classical Gaussian filter (Wahr et al. 1998), and the decorrelation method (Swenson and Wahr 2006), is put forward to process monthly GRACE-derived Stokes coefficients estimated by the Center for Space Research (CSR). Monthly GRACE-derived geopotential coefficients provided by the Groupe de Recherches en Geodesie Spatiale (GRGS) were estimated by means of the truncated singular value decomposition (TSVD) technique which made the post-processing unnecessary (Save et al. 2012). To more accurately detect the water or glacier mass changes over TP, the post-glacial rebound (PGR) effect should be removed by the glacial isostatic adjustment (GIA). We also use the hydrological model to interpret GRACEderived results.

\section{DATA AND DATA PROCESSING}

\subsection{GRACE products of CSR}

The newest GRACE monthly solution (level 2) from CSR is the RL05 model up to degree and order 60 (Bettadpur 2012). These geopotential data can be downloaded by http://isdc.gfz-potsdam.de. GRACE data through January 2003 to December 2012 are used in the paper. The missing data had been replaced by the mean value before and after the missing month with the linear interpolation.

We put forward a combined filter strategy to process CSR GRACE data, as seen in Fig. 2a. Firstly, the statistical filter approach (Davis et al. 2008), 
(a)

(b)

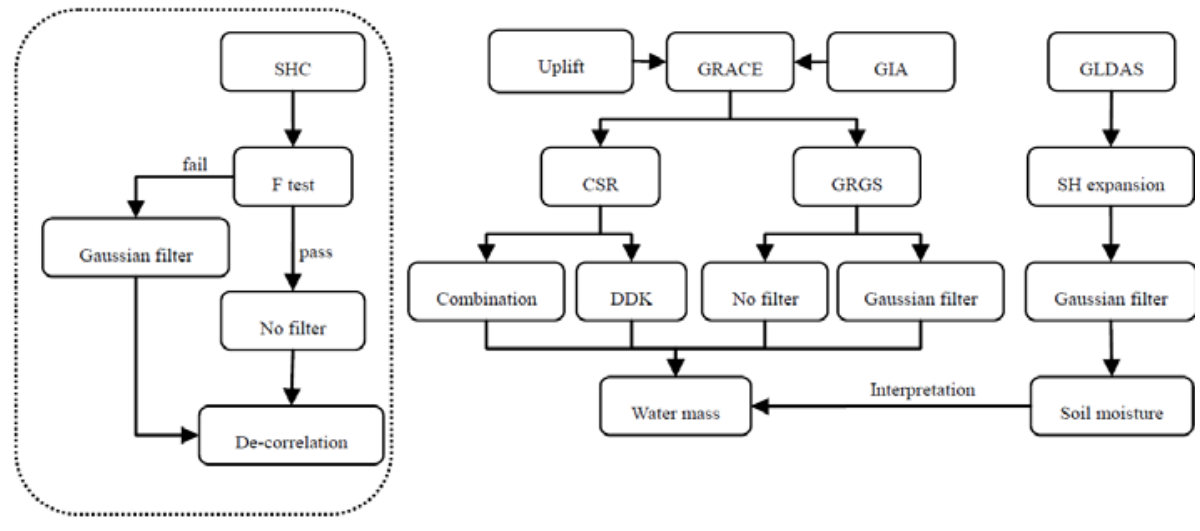

Fig. 2. Data processing designed in this paper. (a) was the combined filter strategy in which SHC represents the time series of GRACE SHC, F test was used in the statistical filter approach to examine the significance level of annual and linear components in GRACE series, and No filter means that the SHC will be kept unchanged. All Gaussian filter radius used in this paper was $300 \mathrm{~km}$; (b) is the flowchart of data processing.

i.e., $\mathrm{F}$ test, is used to examine the significance level of annual and linear components in GRACE spherical harmonic coefficients (SHCs). If the SHCs pass the test, it would be kept unchanged. Otherwise it would be filtered by the Gaussian filter (Wahr et al. 1998). Then we used the de-correlation method (Swenson and Wahr 2006) to remove the correlation errors in GRACE products. Filter methods make the big effect on GRACE-derived results (Werth et al. 2009). As a comparison, the DDK2 filter (Kusche 2007) is used to process CSR geopotential data again. After filtering, GRACE SHCs are converted into the equivalent water height (EWH) (Wahr et al. 1998 ) with the spatial resolution of $1^{\circ} \times 1^{\circ}$.

\subsection{GRGS regularization solutions}

Recently, GRACE RL03 regularization solutions up to degree and order 80 are released by GRGS, which are available at http://grgs.obs-mip.fr/grace. Differing from CSR, GRGS employed TSVD to estimate the GRACE SHCs. It is unnecessary to filter GRGS monthly solutions while used to determine the surface mass anomalies. Even though the TSVD technique may reduce the errors in GRACE SHCs during the process of K-band range rate, we also try to use the post-processing strategy, i.e., the Gaussian filter, to unify the spatial resolution of mass changes. To be consistent with CSR data in the frequency domain, we also truncated the GRGS data to degree and order 60 and then estimated the EWHs over TP. 


\subsection{GLDAS model}

To better interpret and understand GRACE-derived results, the soil moisture is calculated from GLDAS model (Rodell et al. 2004) to represent the surface water change. GLDAS contains the soil moisture within the underground to a depth of $2 \mathrm{~m}$. The original GLDAS data used in this paper are monthly with the spatial resolution of $1^{\circ} \times 1^{\circ}$. In order to agree with GRACE data processing and its spatial resolution, we convert the spatial grids of GLDAS data into the spherical harmonic coefficients (Wahr et al. 1998), and then we use Gaussian filter with the window of $300 \mathrm{~km}$ to process the GLDAS coefficients. In the end, EWHs with grid of $1^{\circ} \times 1^{\circ}$ are estimated by the filtered GLDAS coefficients.

\subsection{GIA model}

GRACE products are largely affected by PGR, especially in Antarctica (Velicogna and Wahr 2006), North America and North Europe, which needs to be corrected by the glacial isostatic adjustment model. Here we used ICE$5 \mathrm{G}$ model (Peltier 2004) which can provide the global uplift rate to estimate the correction for GRACE-derived EWHs.

\section{SPATIAL DISTRIBUTIONS OF GRACE-DERIVED EWHS}

EWHs largely depended on the filter method and parameters from monthly GRACE SHCs (Werth et al. 2009). GRACE models released by different groups - like CSR, Jet Propulsion Laboratory, and GeoForschungsZentrum at Potsdam - will also lead to different results (Guo et al. 2014, Ju et al. 2014, Mu et al. 2014). So it is necessary to evaluate the different GRACE products and methods over TP. Figure 2 shows the flowchart of data processing to estimate water storages over TP. Figure 3 gives the spatial distributions of linear trends over TP determined by: (a) CSR combined filter, (b) CSR DDK2 filter (Kusche 2007), (c) GRGS without filter, and (d) GRGS with the Gaussian filter of 300-km window from 2003 to 2012, respectively. Since GRACE is particularly sensitive to PGR, we remove this effect by ICE-5G model (Peltier 2004). Due to the complicated geodynamics of TP, we have to consider the uplift of TP. Unfortunately, the uplift of TP is not well determined homogenously. Sun et al. (2009) showed that the uplift of whole TP was $1.2 \mathrm{~mm} / \mathrm{yr}$. We use this result to evaluate the effect of TP uplift on GRACE products.

From Fig. 3, we can apparently see that the water mass in TP (especially in the middle and north region) was increasing, and in the Himalayas and the North India it was decreasing from 2003 to 2012, which is consistent with Rodell et al. (2009). In the north TP, an increasing rate of about $5 \mathrm{~mm} / \mathrm{yr}$ is revealed by both the combined filter and DDK2 filter from CSR SHCs. 


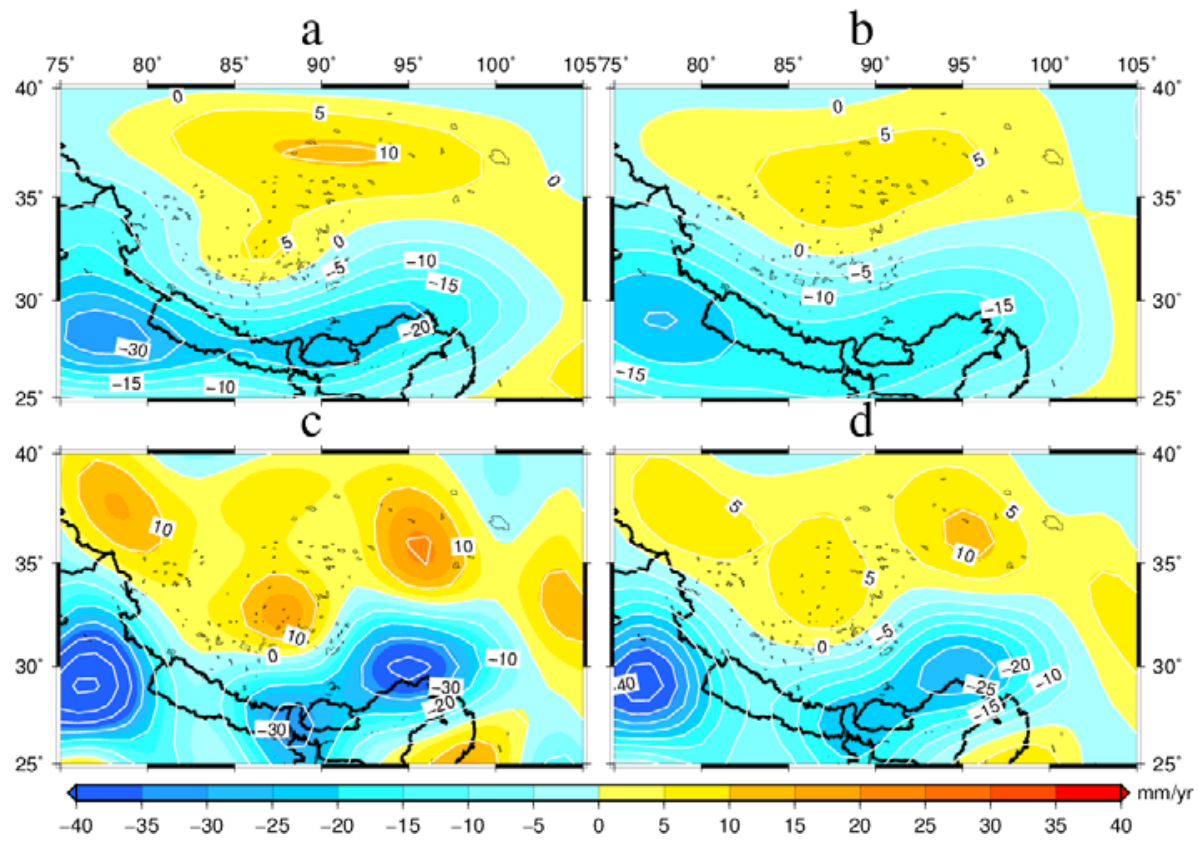

Fig. 3. Linear trends of EWHs derived from GRACE SHCs by: (a) CSR combined filter with window of $300 \mathrm{~km}$, (b) CSR DDK2 filter, (c) GRGS regularization solutions truncated to degree 60 without any filter, and (d) GRGS solutions truncated to degree 60 with the Gaussian filter of $300-\mathrm{km}$ window. The effect of PGR had been removed by using ICE-5G model, and the TP uplift of $1.2 \mathrm{~mm} / \mathrm{yr}$ had been taken into consideration in the figure.

GRGS regularization solution gives more detailed mass change in the middle $\mathrm{TP}$ and the Qaidam Basin where the rate is greater than $10 \mathrm{~mm} / \mathrm{yr}$, as seen in Fig. 3.

It is clear that different filter methods will lead to different results and this is also true for different GRACE SHCs. GRGS processes its own K-band range rates to generate GARCE models instead of using those provided by the GRACE Project (Swenson and Wahr 2011). CSR RL05 data were estimated by the least squares technique whereas GRGS RL03 data were computed using TSVD which made the post-processing (i.e., the filter method) unnecessary (the constraints are mainly made for the high degree; $>30)$.

We considered the effect of uplift (about $1.2 \mathrm{~mm} / \mathrm{yr}$ based on Sun et al. (2009)) in TP and Himalayas. This uplift may be inappropriate because Sun et al. (2009) only used observation data from three stations. In some studies, the effect of uplift was excluded due to the mass loss beneath TP. It is prob- 


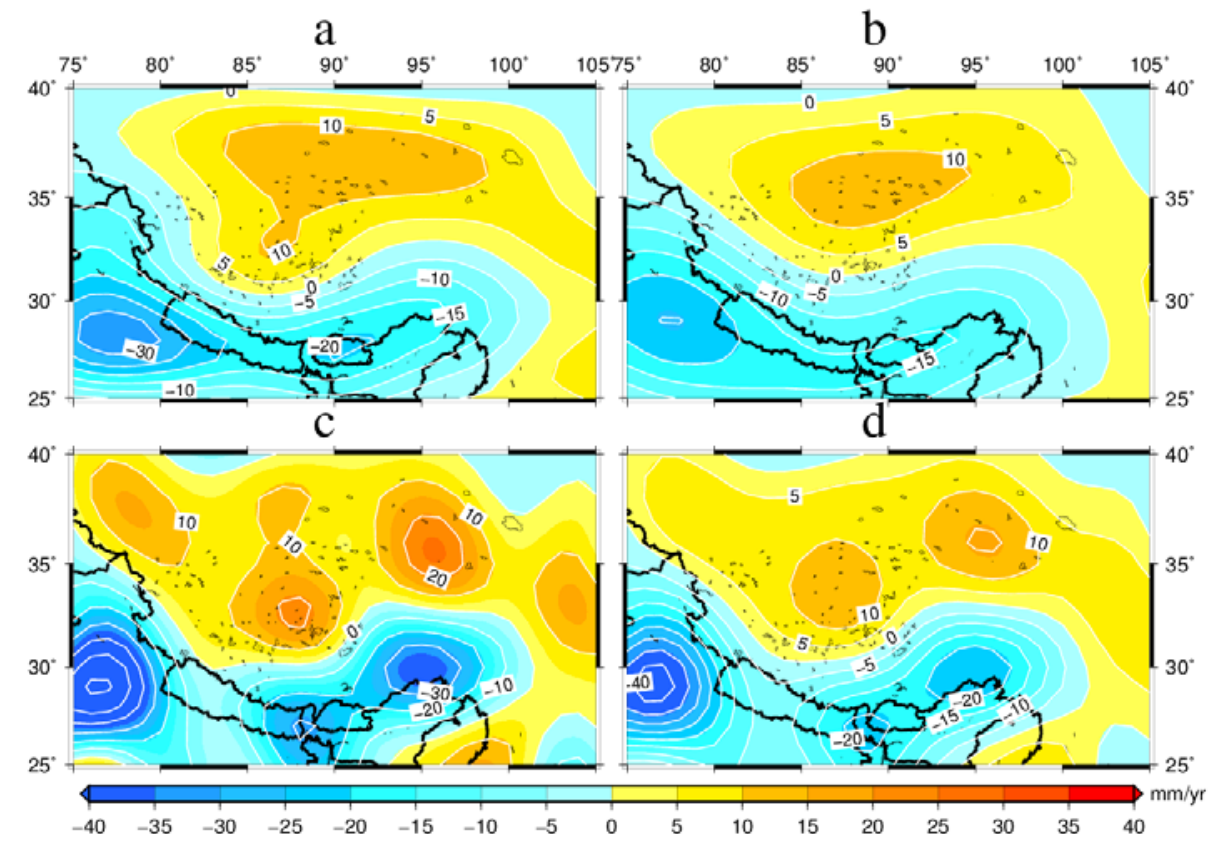

Fig. 4. Linear trends of EWHs derived from GRACE SHCs without the uplift effect: (a) CSR combined filter with window of $300 \mathrm{~km}$, (b) CSR DDK2 filter, (c) GRGS regularization solutions truncated to degree 60 without any filter, and (d) GRGS solutions truncated to degree 60 with the Gaussian filter of $300-\mathrm{km}$ window. The effect of PGR had been removed by using ICE-5G model, and no TP uplift had been taken into consideration in the figure.

able that the large scale tectonic uplift would be compensated by the mass loss which consequently makes no significant contributions to GRACE results (Jacob et al. 2012). The uplift of $1.2 \mathrm{~mm} / \mathrm{yr}$ is roughly equivalent to EHWs of 3-4 mm/yr (Wahr et al. 2000). Figure 4 shows the EWH change trends without the uplift effect. In the north TP, the mass increasing rate from CSR with the combined filter is more than $10 \mathrm{~mm} / \mathrm{yr}$. In the middle TP and Qaidam Basin, this rate determined by GRGS (Fig. 4c, no filter applied) is about $20 \mathrm{~mm} / \mathrm{yr}$. It is apparent that the mass change rate from GRGS became smaller through the Gaussian filtering shown in Fig. 4d. The reason we applied the Gaussian filter to GRGS SHCs is that we want to determine the detailed signal comes from high degree or low degree. Figure $4 d$ indicates that the concentration of mass rate in Fig. $4 \mathrm{c}$ mainly comes from low degree.

GRACE mission can measure the total water storage changes, including soil moisture, groundwater, surface water, ice/snow, and glacier. It is necessary to interpret the geophysical mechanism of water storage increase over 


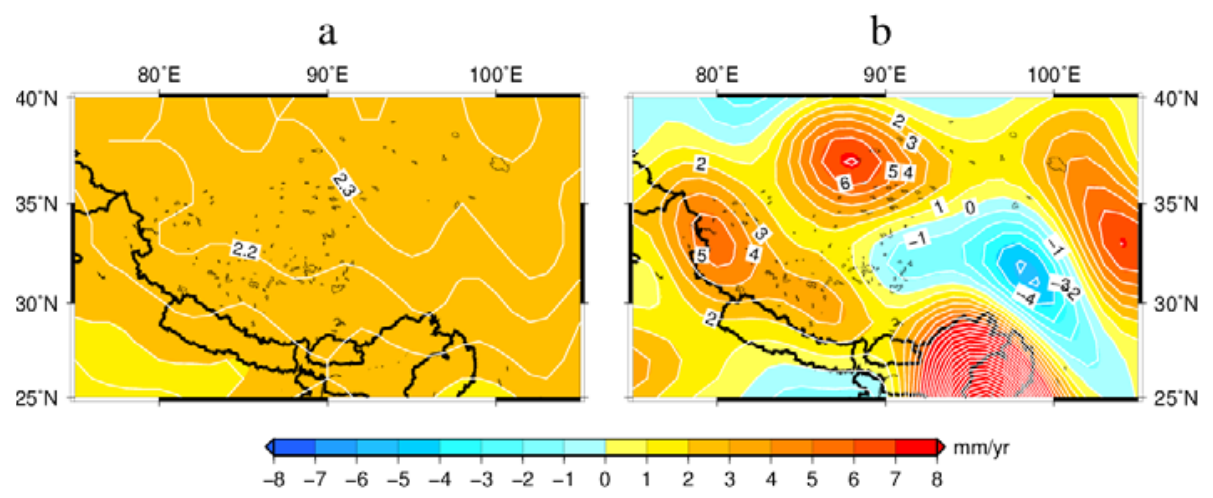

Fig. 5. Effects of PGR and soil moisture: (a) correction for GRACE by ICE-5G model, and (b) soil moisture rate from GLDAS model with the Gaussian filter of 300-km window.

TP. Since PGR may have the positive effect on GRACE-derived EWHs, we use ICE-5G model to evaluate it. In TP, PGR contributes about 2.2$2.3 \mathrm{~mm} / \mathrm{yr}$ (Fig. 5a) to GRACE-derived results and this value has been corrected. Due to the limitation of data availability, we only computed the surface water using GLDAS model (Fig. 5b).

We used the $300-\mathrm{km}$ Gaussian filter to process GLDAS model (see Fig. 2) to agree with the GRACE resolution. In the north TP, GLDAS had an increasing rate with 4-6 mm/yr, which was consistent with GRACE products. We can conclude that water increase in the north TP may be caused by the surface water. Of course, this conclusion is not rigorous since water changes are very complicated.

\section{REGIONAL WATER STORAGE CHANGES}

EWHs of five regions selected in TP and surrounding area (see Fig. 1) will be analyzed in detail. Five series of EWHs are shown in Fig. 6 where CSR means the results derived by the combined filter and GRGS results are filtered by the Gaussian smoothing with the window of $300 \mathrm{~km}$. Table 1 gives the linear and period changes determined by the least square fitting.

Region ' $a$ ' is located in the Karakoram Mountain where the mass increase rate is about $6 \mathrm{~mm} / \mathrm{yr}$ and the rate difference between CSR and GRGS results is very small (see Table 1). Comparing to the mass loss in the Pamir Plateau, the mass increase in the Karakoram is called the Karakoram anomaly which is mainly caused by the glacier accumulation. Water storages over the Qaidam Basin (region ' $b$ ') and the interior TP (region ' $c$ ') are all increasing with the rates of 9.1 and $9.7 \mathrm{~mm} / \mathrm{yr}$, respectively, from the CSR results with the combined filter, see Table 1. 

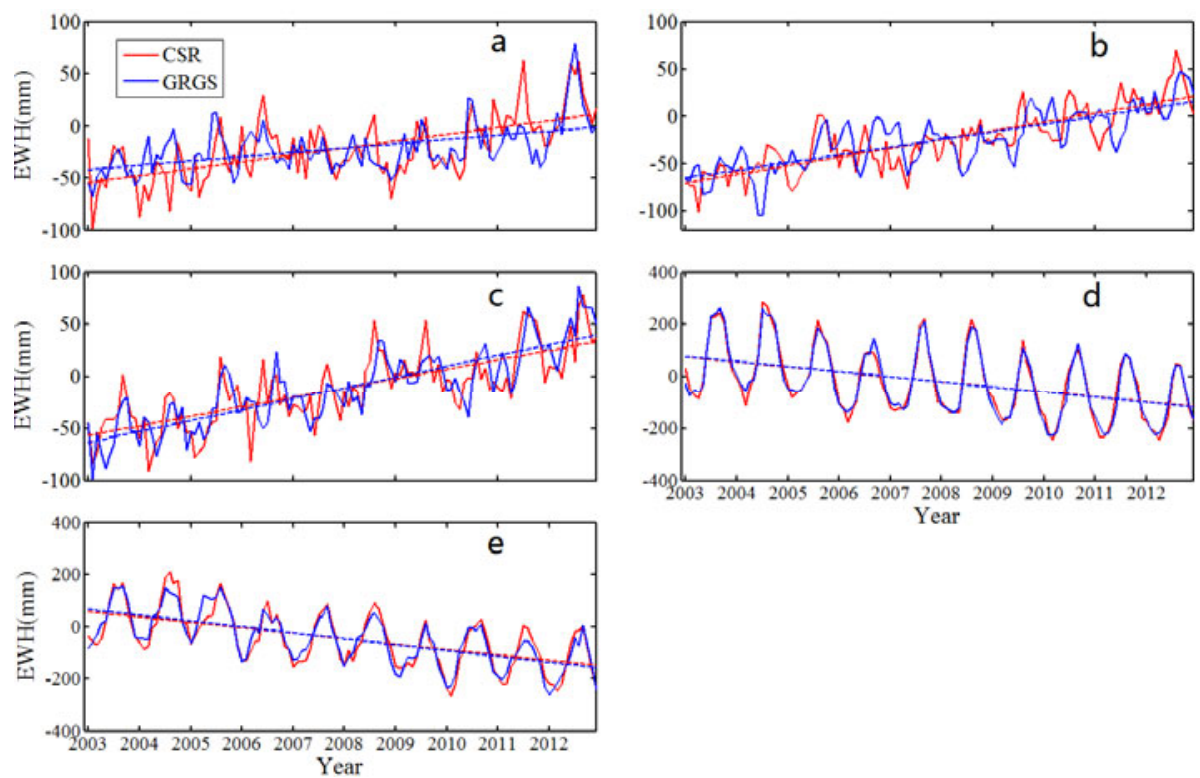

Fig. 6. EWHs in five selected regions: (a) Karakoram, (b) Qaidam, (c) the middle TP, (d) Hengduan, and (e) the middle of Himalayas. Here CSR means the combined filter results and GRGS were filtered by the Gaussian filter with window of $300 \mathrm{~km}$. The data processing same as in Fig. 5.

Table 1

Least squares spectral analysis of water storages in five selected regions:

$\mathrm{a}$ - Karakoram, $\mathrm{b}$ - Qaidam, $\mathrm{c}$ - the middle TP, $\mathrm{d}-$ Hengduan, and $\mathrm{e}-$ the middle of Himalayas (see Fig. 1)

\begin{tabular}{|c|l|c|c|c|c|c|}
\hline Region & Data & $\begin{array}{c}\text { Rate } \\
{[\mathrm{mm} / \mathrm{yr}]}\end{array}$ & $\begin{array}{c}\text { AA } \\
{[\mathrm{mm}]}\end{array}$ & $\begin{array}{c}\text { AP } \\
{[\mathrm{month}]}\end{array}$ & $\begin{array}{c}\text { SA } \\
{[\mathrm{mm}]}\end{array}$ & $\begin{array}{c}\text { SP } \\
{[\mathrm{month}]}\end{array}$ \\
\hline \multirow{2}{*}{$\mathrm{a}$} & CSR & 6.2 & 17 & -1.2 & 4 & 0.2 \\
& GRGS & 5.8 & 19 & -1.6 & 5 & 0.3 \\
\hline \multirow{2}{*}{$\mathrm{b}$} & CSR & 9.1 & 18 & -1.9 & 6 & 0.4 \\
& GRGS & 10.5 & 16 & -1.8 & 5 & -0.1 \\
\hline \multirow{2}{*}{$\mathrm{c}$} & CSR & 9.7 & 16 & -2.9 & 5 & -0.3 \\
& GRGS & 8.6 & 16 & -2.7 & 12 & -1.7 \\
\hline \multirow{2}{*}{$\mathrm{d}$} & CSR & -18.6 & 102 & -2.5 & 9 & -1.6 \\
& GRGS & -19.3 & 95 & -2.3 & 20 & -2.1 \\
\hline \multirow{2}{*}{$\mathrm{e}$} & CSR & -20.2 & 143 & -2.9 & 31 & -0.6 \\
& GRGS & -21.4 & 146 & -3.1 & 30 & -0.8 \\
\hline
\end{tabular}

Explanations: AA stands for the annual amplitude, AP is the annual phase, SA is the semi-annual amplitude, SP is the semi-annual phase; CSR was filtered by the combined filter and GRGS was processed by the $300-\mathrm{km}$ Gaussian filter. 
From Fig. 6 and Table 1, we can find that the linear trends of EWH over regions ' $a$ ', ' $b$ ', and ' $c$ ' are very significant and the annual amplitudes are relatively small. AAs over regions 'a', 'b', and 'c' are less than $20 \mathrm{~mm}$. Region ' $b$ ' is located in the Qaidam Basin and region ' $c$ ' is at the middle TP where there are lots of lakes. Considering the geographical environments of regions ' $b$ ' and ' $c$ ', we can infer that the water storage increase in regions ' $b$ ' and ' $c$ ' may be mainly caused by the surface water (soil moisture, lake water, and runoff) instead of the glacier, which is consistent with Song et al. (2013).

The annual variations and the linear trends of EWHs in regions ' $d$ ' (Hengduan Mountain) and 'e' (the middle Himalayas) are very obvious as shown in Fig. 6 and Table 1. AAs in regions ' $d$ ' and 'e' are greater than 90 and $140 \mathrm{~mm}$, respectively, which indicates that the thaw and freezing of glacier are very strong. This may be related to the warming trend, especially in summer. Except for AA, the mass loss rates of regions ' $d$ ' (-18.6 and $19.3 \mathrm{~mm} / \mathrm{yr}$ inferred from CSR and GRGS, respectively) and 'e' (-20.2 and $-21.4 \mathrm{~mm} / \mathrm{yr}$ inferred from CSR and GRGS, respectively) are also triggered by the warming trends.

One point should be noted, namely, that the regional water storage changes with the strong geophysical signal, i.e., EWH anomaly, detected by different GRACE products and methods may have little differences as compared to TP investigated in this paper. On one hand, the geophysical signal (e.g., water mass changes which is our interests), uplift of TP, GIA, and mass loss beneath TP, are hard to be independently separated from GRACE products without other auxiliary information. On the other hand, the filter method for SHCs and the data processing during Level-1B may also contaminate the feeble signals.

\section{DISCUSSION}

As revealed in this paper and others (e.g., Jacob et al. 2012 and Yi and Sun 2014), GRACE shows that the water mass over TP was increasing for the period 2003-2012. Other independent remote data also confirmed this conclusion. In the interior TP, the satellite altimetry technique demonstrated that the water levels of most lakes were gradually increasing (Song et al. 2013, Zhang et al. 2011). Satellite imageries also revealed that the number of lakes, especially glacial lakes, is increasing (Wang et al. 2013). This tells us that the positive signal in TP was not only from the soil moisture but also from lakes (Zhang et al. 2013). This leads to another interesting question: where does the lake water or the soil moisture comes from? The previous studies demonstrated that TP had been experiencing the warming trends since the 1980s (Rangwala et al. 2009). The surface air warming, moistening 
and solar dimming would trigger the more convective precipitation, especially over the central TP (Yang et al. 2014). Of course, the relation of precipitation and water increase needs to be examined by using more data.

In theory, the filter method is equal to the regularization solution (Swenson and Wahr 2011). The difference between these two techniques is to constrain the SHC before or after deriving SHC (Save et al. 2012, Eshagh et al. 2013). But in practice, different choices of parameter and solution approach will generate different results (Werth et al. 2009), e.g., the water storage change in TP, as shown in this paper. It is easy to understand that feeble signal is very sensitive to the filter parameter and method. The merit of our combined filter is that it can keep the linear and annual signal because of the usage of statistical method (Davis et al. 2008). Our estimates of water increase rate for TP $(5.3 \mathrm{Gt} / \mathrm{yr}$, based on our combination filter method) agree more with Jacob et al. (2012; 7Gt/yr) than Yi and Sun (2014; 30Gt/yr). Given the precipitation data and other remote sensing data, the increase rate of $30 \mathrm{Gt} / \mathrm{yr}$ is hard to interpret reasonably. One possible reason for the $30 \mathrm{Gt} / \mathrm{yr}$ is that the observation grids used in Yi and Sun (2014) might be inappropriate (one degree grids over the entire Asia may overestimate the ice mass change, see more details in Yi and Sun 2014).

In the Himalaya, different GRACE products and methods agree generally better than in other regions (Fig. 4). But the EWHs estimated by GRGS are bigger than CSR (no matter filtered by combined filter or DDK filter). One possible explanation is that CSR data might have been over-smoothed. A simple test is to use the lower smooth radius (e.g., $150 \mathrm{~km}$ Gaussian filter) to process CSR data (Jacob et al. 2012). If this procedure is introduced, an extra examination or comparison (with other independent data) must be done to make sure that the result is reliable.

\section{CONCLUSIONS}

GRACE data have revealed that the water storage over TP was increasing during 2003-2012. The combined filter strategy presented in this paper is more practical than the traditional Gaussian filter because the trend signal would be less attenuated. Compared with the mass loss of $30 \mathrm{Gt} / \mathrm{yr}$ in TP given by Yi and Sun (2014), our result of loss rate $5.3 \mathrm{Gt} / \mathrm{yr}$ was close to $7 \mathrm{Gt} / \mathrm{yr}$ (Jacob et al. 2012).

Different GRACE products and filter methods will lead to different results when the regional signal is relatively small, especially in TP, as shown in this paper. Compared with CSR data, GRGS regularization solutions give more detailed changes over TP (two centered mass changes in interior of TP) and the post-processing strategy is not necessary for GRGS. The geodynamics over TP is very complicated. The uplift of TP, effect of PGR, and mass 
loss beneath the TP will amplify the uncertainties of GRACE results. One potential technique for better understanding the glacier variations over TP is the reconciled estimate method (Gardner et al. 2013), which of course depends on the data availability.

Acknowledgements. We are very grateful to the anonymous reviewers for their proposals and comments. We thank CSR and GRGS for providing GRACE data. This research is partially supported by the National Natural Science Foundation of China (grant No. 41374009), the Public Benefit Scientific Research Project of China (grant No. 201412001), the Shandong Natural Science Foundation of China (grant No. ZR2013DM009), the National Basic Research Program of China (grant No. 2013CB733302), and the SDUST Research Fund (grant No. 2014TDJH101).

\section{References}

Bettadpur, S. (2012), UTCSR Level-2 processing standards document for level-2 product release 05, Rev. 4.0, Center for Space Research, The University of Texas at Austin, USA.

Davis, J.L., M.E. Tamisiea, P. Elósegui, J.X. Mitrovica, and E.M. Hill (2008), A statistical filtering approach for Gravity Recovery and Climate Experiment (GRACE) gravity data, J. Geophys. Res. 113, B4, B04410, DOI: 10.1029/ 2007JB005043.

Eshagh, M., J.-M. Lemoine, P. Gegout, and R. Biancale (2013), On regularized time varying gravity field models based on GRACE data and their comparison with hydrological models, Acta Geophys. 61, 1, 1-17, DOI: 10.2478/s11600 $-012-0053-5$.

Gardelle, J., E. Berthier, Y. Arnaud, and A. Kääb (2013), Region-wide glacier mass balances over the Pamir-Karakoram-Himalaya during 1999-2011, The Cryosphere 7, 6, 1263-1286, DOI: 10.5194/tc-7-1263-2013.

Gardner, A.S., G. Moholdt, J.G. Cogley, B. Wouters, A.A. Arendt, J. Wahr, E. Berthier, R. Hock, W.T. Pfeffer, G. Kaser, S.R.M. Ligtenberg, T. Bolch, M.J. Sharp, J.O. Hagen, M.R. van den Broeke, and F. Paul (2013), A reconciled estimate of glacier contributions to sea level rise: 2003 to 2009, Science 340, 6134, 852-857, DOI: 10.1126/science.1234532.

Guo, J., D. Mu, X. Liu, H. Yan, and H. Dai (2014), Equivalent water height extracted from GRACE gravity field model with robust independent component analysis, Acta Geophys. 62, 4, 953-972, DOI: 10.2478/s11600-0140210-0.

Jacob, T., J. Wahr, W.T. Pfeffer, and S. Swenson (2012), Recent contributions of glaciers and ice caps to sea level rise, Nature 482, 7386, 514-518, DOI: 10.1038/nature10847. 
Ju, X.L, Y.Z. Shen, and Z.Z. Zhang (2014), GRACE RL05-based ice mass changes in the typical regions of Antarctica from 2004 to 2012, Geodesy Geodynam. 5, 4, 57-67, DOI: 10.3724/SP.J.1246.2014.04057.

Kääb, A., E. Berthier, C. Nuth, J. Gardelle, and Y. Arnaud (2012), Contrasting patterns of early twenty-first-century glacier mass change in the Himalayas, Nature 488, 7412, 495-498, DOI: 10.1038/nature11324.

Kusche, J. (2007), Approximate decorrelation and non-isotropic smoothing of timevariable GRACE-type gravity field models, J. Geodesy 81, 11, 733-749, DOI: 10.1007/s001190-007-0143-3.

Matsuo, K., and K. Heki (2010), Time-variable ice loss in Asian high mountains from satellite gravimetry, Earth Planet. Sci. Lett. 290, 1-2, 30-36, DOI: 10.1016/j.epsl.2009.11.053.

Mu, D.P., J.Y. Guo, Z.C. Sun, and Q.L. Kong (2014), Equivalent water height from GRACE gravity model based on principal component analysis, Prog. Geophys. 29, 4, 1512-1517, DOI: 10.6038/pg20140405.

Peltier, W.R. (2004), Global glacial isostasy and the surface of the ice-age Earth: the ICE-5G (VM2) model and GRACE, Ann. Rev. Earth Planet. Sci. 32, 111149, DOI: 10.1146/annurev.earth.32.082503.144359.

Rangwala, I., J.R. Miller, and M. Xu (2009), Warming in the Tibetan Plateau: Possible influences of the changes in surface water vapor, Geophys. Res. Lett. 36, 6, L06703, DOI: 10.1029/2009GL037245.

Rodell, M., P.R. Houser, U. Jambor, J. Gottschalck, K. Mitchell, C-J. Meng, K. Arsenault, B. Cosgrove, J. Radakovich, M. Bosilovich, J.K. Entin, J.P. Walker, D. Lohmann, and D. Toll (2004), The global land data assimilation system, Bull. Am. Meteorol. Soc. 85, 3, 381-394, DOI: 10.1175/ BAMS-85-3-381.

Rodell, M., I. Velicogna, and J.S. Famiglietti (2009), Satellite-based estimates of groundwater depletion in India, Nature 460, 999-1002, DOI: 10.1038/ nature 08238 .

Save, H., S. Bettadpur, and B.D. Tapley (2012), Reducing errors in the GRACE gravity solutions using regularization, $J$. Geodesy 86, 9, 695-711, DOI: 10.1007/s00190-012-0548-5.

Song, C., B. Huang, and L. Ke (2013), Modeling and analysis of lake water storage changes on the Tibetan Plateau using multi-mission satellite data, Remote Sens. Environ. 135, 25-35, DOI: 10.1016/j.rse.2013.03.013.

Sun, W., Q. Wang, H. Li, Y. Wang, S. Okubo, D. Shao, D. Liu, and G. Fu (2009), Gravity and GPS measurements reveal mass loss beneath the Tibetan Plateau: Geodetic evidence of increasing crustal thickness, Geophys. Res. Lett. 36, 2, L02303, DOI: 10.1029/2008GL036512.

Swenson, S., and J. Wahr (2006), Post-processing removal of correlated errors in GRACE data, Geophys. Res. Lett. 33, 8, L08402, DOI: 10.1029/ 2005 GL025285. 
Swenson, S.C., and J.M. Wahr (2011), Estimating signal loss in regularized GRACE gravity field solutions, Geophys. J. Int. 185, 2, 693-702, DOI: 10.1111/ j.1365-246X.2011.04977.x.

Tapley, B.D., S. Bettadpur, J.C. Ries, P.F. Thompson, and M.M. Watkins (2004), GRACE measurements of mass variability in the Earth system, Science 305, 5683, 503-505, DOI: 10.1126/science.1099192.

Velicogna, I., and J. Wahr (2006), Acceleration of Greenland ice mass loss in spring 2004, Nature 443, 7109, 329-331, DOI: 10.1038/nature05168.

Wahr, J., M. Molenaar, and F. Bryan (1998), Time variability of the Earth's gravity field: hydrological and oceanic effects and their possible detection using GRACE, J. Geophys. Res. 103, B12, 30205-30229, DOI: 10.1029/ 98JB02844.

Wahr, J., D. Wingham, and C. Bentley (2000), A method of combining ICESat and GARCE satellite data to constrain Antarctic mass balance, J. Geophys. Res. 105, B7, 16279-16294, DOI: 10.1029/2000JB900113.

Wang, X., F. Siegert, A.G. Zhou, and J. Franke (2013), Glacier and glacial lake changes and their relationship in the context of climate change, Central Tibetan Plateau 1972-2010, Global Planet. Change 111, 246-257, DOI: 10.1016/j.gloplacha.2013.09.011.

Werth, S., A. Güntner, R. Schmidt, and J. Kusche (2009), Evaluation of GRACE filter tools from a hydrological perspective, Geophys. J. Int. 179, 3, 14991515, DOI: 10.1111/j.1365-246X.2009.04355.x.

Yang, K., H. Wu, J. Qin, C. Lin, W. Tang, and Y. Chen (2014), Recent climate changes over the Tibetan Plateau and their impacts on energy and water cycle: A review, Global Planet Change 112, 79-91, DOI: 10.1016/j.gloplacha. 2013.12.001.

Yao, T.D., D.H. Qin, Y.P. Shen, L. Zhao, N.L. Wang, and A.X. Lu (2013), Cryospheric changes and their impacts on regional water cycle and ecological conditions in the Qinghai-Tibetan Plateau, Chin. J. Nat. 35, 3, 179-186.

Yi, S., and W. Sun (2014), Evaluation of glacier changes in high-mountain Asia based on 10 year GARCE RL05 models, J. Geophys. Res. 119, 3, 25042517, DOI: 10.1002/2013JB010860.

Zhang, G., H. Xie, S. Kang, D. Yi, and S.F. Ackley (2011), Monitoring lake level changes on the Tibetan Plateau using ICESat altimetry data (2003-2009), Remote Sens. Environ. 115, 7, 1733-1742, DOI: 10.1016/j.rse.2011.03.005.

Zhang, G., T. Yao, H. Xie, S. Kang, and Y. Lei (2013), Increased water over the Tibetan Plateau: From lakes or glaciers? Geophys. Res. Lett. 40, 10, 2125 2130, DOI: $10.1002 /$ grl.50462. 